\title{
Reduced Pulsatility Induces Periarteritis in Kidney: Role of the Local Renin-Angiotensin System
}

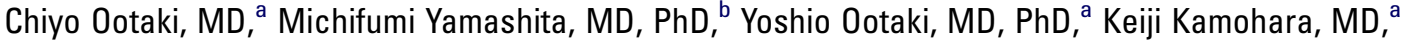 \\ Stephan Weber, Dipl Ing, ${ }^{a}$ Ryan S. Klatte, BSBME, ${ }^{a}$ William A. Smith, DEng, PE, ${ }^{a}$ Alex L. Massiello, MEBME, \\ Steven N. Emancipator, MD, ${ }^{b}$ Leonard A. R. Golding, MD, and Kiyotaka Fukamachi, MD, PhD ${ }^{a}$
}

Objective: The need for pulsatility in the circulation during long-term mechanical support has been a subject of debate. We compared histologic changes in calf renal arteries subjected to various degrees of pulsatile circulation in vivo. We addressed the hypothesis that the local renin-angiotensin system may be implicated in these histologic changes.

Methods and Results: Sixteen calves were implanted with devices giving differing degrees of pulsatile circulation: 6 had a continuous flow left ventricular assist device (LVAD); 6 had a continuous flow right ventricular assist device (RVAD); and 4 had a pulsatile total artificial heart (TAH). Six other calves were histologic and immunohistochemical controls. In the LVAD group, the pulsatility index was significantly lower $(0.28 \pm 0.07 \mathrm{LVAD}$ vs $0.56 \pm 0.08 \mathrm{RVAD}$, vs $0.53 \pm 0.10 \mathrm{TAH} ; P<$ 0.01 ), and we observed severe periarteritis in all cases in the LVAD group. The number of angiotensin II type 1 receptor-positive cells and angiotensin converting enzyme-positive cells in periarterial areas was significantly higher in the LVAD group (angiotensin II type 1 receptor: $350 \pm 139$ LVAD vs $8 \pm 6$ RVAD, vs $3 \pm$ $2 \mathrm{TAH}$, vs $3 \pm 2$ control; $P<.001$; angiotensin-converting enzyme: $325 \pm 59$ LVAD vs $6 \pm 4$ RVAD, vs $6 \pm 5$ TAH, vs $3 \pm 1$ control; $P<.001)$.

Conclusions: The reduced pulsatility produced by a continuous flow LVAD implantation induced severe periarteritis in the kidneys. The local renin-angiotensin system was up-regulated in the inflammatory cells only in the continuous flow LVAD group.

From the Department of Biomedical Engineering, Lerner Research Institute, Cleveland Clinic, ${ }^{\text {a }}$ and the Department of Pathology, Case Western Reserve University, Cleveland, Ohio

Received for publication July 9, 2007; revisions received Nov 11, 2007; accepted for publication Dec 6, 2007.

Address for reprints: Kiyotaka Fukamachi, $\mathrm{MD}, \mathrm{PhD}$, Department of Biomedical Engineering/ND20, The Cleveland Clinic, 9500 Euclid Ave, Cleveland, OH 44195 (E-mail: fukamak@ccf.org).

J Thorac Cardiovasc Surg 2008;136:150-8 $0022-5223 / \$ 34.00$

Copyright $(\subset) 2008$ by The American Association for Thoracic Surgery

doi:10.1016/j.jtcvs.2007.12.023
$\mathrm{T}$ The necessity of maintaining pulsatility in the systemic circulation during longterm mechanical support has been a subject of debate. Recently, simpler and smaller continuous flow blood pumps have become more prevalent. The diminished pulsatility created by support from a continuous flow left ventricular assist device (LVAD) is physiologically abnormal, and some changes to the structure of the aortic wall and the renal artery have been reported. ${ }^{1,2}$ Continuous flow LVAD support has been reported to cause renal cortical artery hypertrophy and inflammatory cell infiltration in the renal cortex. ${ }^{2}$ However, the mechanisms leading to those morphologic changes are still unclear.

In this study, we examined the renal arteries of calves implanted with several different types of circulatory support devices delivering various degrees of systemic arterial pulsatility. We observed severe inflammatory and morphologic changes in the kidney only in those calves with continuous flow LVADs. In addition to its pressor effect, angiotensin II (Ang II), the physiologically active component of the renin-angiotensin system (RAS), has a variety of nonhemodynamic actions, including cell growth, as well as proinflammatory and profibrogenic actions through the Ang II type 1 receptors (AT1R). ${ }^{3}$ Many of these actions are associated with cardiovascular and renal disease. ${ }^{4}$ Many tissues are thought to be capable of local Ang II production via the tissue-specific local RAS. ${ }^{5-9}$ This locally produced Ang II acts on tissue through resident Ang II receptors. We directed our attention to the local RAS as 


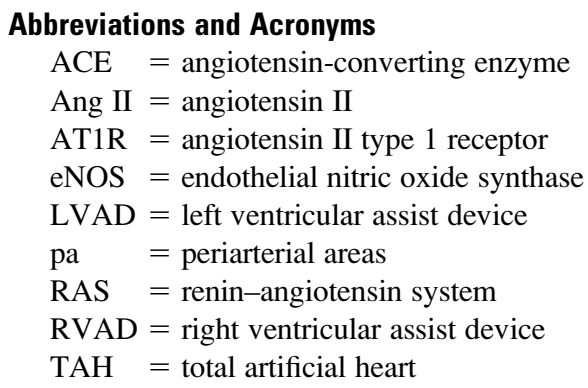

a possible mechanism for those pathologic changes, and we demonstrated by immunohistochemical analysis that AT1R and angiotensin-converting enzyme (ACE) were found in inflammatory cells that had infiltrated the kidneys of calves with continuous flow LVADs.

\section{Methods}

\section{Animals and Device Description}

Twenty-two male Holstein calves $(99.8 \pm 16.7 \mathrm{~kg})$ were used in this study. A continuous flow LVAD was implanted in 6 calves, creating the condition of reduced systemic arterial pulsatile perfusion; a continuous flow right ventricular assist device (RVAD) was implanted in 6 calves, representing the condition of pulsatile perfusion and as a biomaterial control. The RVAD did produce reduced pulsatility in the pulmonary circulation; however, pulsatility was maintained in the systemic circulation. A pulsatile total artificial heart (TAH) was implanted in 4 calves to study pulsatile perfusion. Six normal calves were used as normal histologic and immunohistochemical controls. As shown in Table 1, the devices were implanted for various durations ranging from 22 to 95 days.

\section{Animal Care}

This study was approved by the Cleveland Clinic's Institutional Animal Care and Use Committee, and all animals received humane care in compliance with the "Guide for the Care and Use of Laboratory Animals" prepared by the Institute of Laboratory Animal Resources, National Research Council, and published by the National Academy Press, revised 1996.

\section{Implant Procedure}

On arrival at the facility, all calves were quarantined for at least 14 days in the Biological Resources Unit. The calves were fasted for 12 hours before surgery. Anesthesia was induced with ketamine, 10 $\mathrm{mg} / \mathrm{kg}$ intramuscularly, and isoflurane via mask inhalation. Each animal was then intubated, and anesthesia was maintained with isoflurane $(1.0 \%-2.0 \%)$ and oxygen.

\section{LVAD Implantation}

The CorAide continuous flow left ventricular assist system (Arrow International, Reading, Pa), originally developed at the Cleveland Clinic, is a centrifugal continuous flow pump. ${ }^{10}$ Through a left thoracotomy, the outflow graft of the pump was anastomosed to the descending aorta, and the inflow cannula of the pump was inserted
TABLE 1. Characteristics of calves with mechanical support devices and normal control calves

\begin{tabular}{lccc}
\hline & No. & Implant duration (d) & Body weight (kg) \\
\hline $\operatorname{LVAD}(\mathrm{n}=6)$ & 1 & 39 & 84.0 \\
& 2 & 29 & 93.0 \\
& 3 & 31 & 83.0 \\
& 4 & 31 & 86.0 \\
& 5 & 30 & 92.0 \\
& 6 & 95 & 83.0 \\
$\operatorname{RVAD}(\mathrm{n}=6)$ & Avg. & $42.5 \pm 26.0$ & $86.8 \pm 4.5$ \\
& 1 & 30 & 93.0 \\
& 2 & 29 & 96.0 \\
& 3 & 25 & 160.0 \\
& 4 & 22 & 95.6 \\
& 5 & 30 & 96.9 \\
& 6 & 30 & 113.2 \\
$\operatorname{TAH}(\mathrm{n}=4)$ & Avg. & $27.7 \pm 3.4$ & $109.1 \pm 26.0$ \\
& 1 & 83 & 105.0 \\
& 2 & 28 & 113.0 \\
& 3 & 92 & 110.5 \\
& 4 & 67 & 110.0 \\
Control $(\mathrm{n}=6)$ & 1 & $67.5 \pm 28.3$ & $109.6 \pm 3.4$ \\
& 2 & - & 100.0 \\
& 3 & - & 90.0 \\
& 4 & - & 90.0 \\
& 5 & - & 110.5 \\
& 6 & - & 90.0 \\
& Avg. & - & 101.0 \\
& & & $96.9 \pm 8.4$ \\
\hline
\end{tabular}

$\angle V A D$, Left ventricular assist device; RVAD, right ventricular assist device; $T A H$, total artificial heart.

into the left ventricle. An ultrasonic perivascular flow probe (Transonic Systems Inc, Ithaca, NY) was placed around the outflow graft for continuous monitoring of the pump output. Arterial pressure was measured in the carotid artery by a fluid-filled pressure-monitoring line. After surgery, intravenous nitroprusside was administered to maintain mean arterial pressure at less than $125 \mathrm{~mm} \mathrm{Hg}$ and pump flows at greater than $3.5 \mathrm{~L} / \mathrm{min}$.

\section{RVAD Implantation}

The Cleveland Clinic's DexAide blood pump is a centrifugal, continuous flow blood pump, constructed of the same materials as the CorAide left ventricular assist system, ${ }^{11}$ but with a modified design. Through a left thoracotomy, the outflow graft of the pump was anastomosed to the pulmonary artery, and the inflow cannula of the pump was inserted into the right ventricle under cardiopulmonary bypass support. An ultrasonic perivascular flow probe was placed around the outflow graft. Systemic arterial pressure was measured in the carotid artery by a fluid-filled pressure-monitoring line. After cardiopulmonary bypass was discontinued, the RVAD was initiated.

\section{TAH Implantation}

The Cleveland Clinic's MagScrew TAH is an implantable pulsatile TAH system. ${ }^{12}$ A right fourth intercostal thoracotomy was performed. Under cardiopulmonary bypass support, the native ventricles 
were removed. The right and left outflow grafts were anastomosed to the main pulmonary artery and the ascending aorta, respectively, and the inflow cuffs were anastomosed to the left and right atria. Bioprosthetic valves (Edwards Lifesciences 6900 P series; Edwards Lifesciences, Inc, Irvine, Calif) were placed into the inflow and outflow portions of the TAH. Systemic arterial pressure was measured in the carotid artery by a fluid-filled pressure-monitoring line. As cardiopulmonary bypass was discontinued, the TAH was initiated.

\section{Postoperative Hemodynamic Data and Renal Function}

After the operation, the calves were transferred to a long-term care facility and maintained in cages with continuous hemodynamic monitoring. An Astro-Med MT95K2 16-channel data acquisition and recording system (Astro-Med, Inc, West Warwick, RI) continuously recorded arterial pressure, electrocardiogram, and pump flow. Mean values for arterial pressure, pump flow, and pump speed were recorded hourly. Systemic arterial pressure pulsatility was quantified by pulse pressure (systolic pressure - diastolic pressure) and pulsatility index (pulse pressure/mean arterial pressure). Renal function was evaluated weekly by blood urea nitrogen and serum creatinine analysis.

\section{Autopsy}

At the completion of each study, after full heparinization $(500 \mathrm{U} / \mathrm{kg}$ bolus injection), the animal was humanely killed with an overdose of sodium pentobarbital $(5000 \mathrm{mg})$ and potassium chloride $(240$ $\mathrm{mEq}$ ), and a thorough autopsy was performed. The renal tissue specimens included medulla and cortex samples from both the right and left kidneys.

\section{Pathologic Study}

All renal tissue specimens were fixed in $10 \%$ formaldehyde. Transverse sections $4-\mu \mathrm{m}$ thick were stained with hematoxylin and eosin and periodic acid-Schiff for light microscopy evaluation. To quantify morphologic changes, we scanned hematoxylin and eosinstained sections at $100 \times$ magnification with a light microscope equipped with Retiga Exi Fast 1394 camera (Qimaging, Burnaby, British Columbia, Canada). The arterial wall diameter, wall thickness, wall thickness/wall diameter ratio, wall cross-sectional area, and ratio of smooth muscle layer cross-sectional area/number of smooth muscle cells were measured on all arteries in the renal corticomedullary junction with Image-Pro Plus (Media Cybernetics, Silver Spring, Md). The average values for each animal were reported as an average of the 20 to 40 arterial cross sections examined. The wall area was defined as the region between the endothelium and external elastic lamina. The smooth muscle layer was defined as the region between the internal and external elastic lamina. The wall cross-sectional area of the renal arteries was defined as the mean of the measurements of the two opposite walls in the direction of the minimal diameter, since that was the direction in which measurements are least affected by the sectioning angle. ${ }^{13}$

\section{Immunohistochemical Study}

Sections $4-\mu \mathrm{m}$ thick, cut from paraffin blocks of the renal tissues, were used. The tissue sections were immunostained by rabbit anti-AT1R antibody (ab18801; Abcam, Cambridge, United Kingdom), angiotensin-converting enzyme mouse anti-ACE antibody
(MAB3502; Chemicon, Temecula, Calif), and by rabbit polyclonal to endothelial nitric oxide synthase (eNOS) (ab5589; Abcam). The tissue sections were deparaffinized in xylene and descending grades of alcohol. The antigen was retrieved by treating the slides in 10 $\mathrm{mmol} / \mathrm{L}$ citrate buffer, $\mathrm{pH} 6.0$, in a $120^{\circ} \mathrm{C}$ autoclave for 5 minutes (for ACE antibody and eNOS) or in $0.025 \%$ trypsin and $0.1 \%$ $\mathrm{CaCl}_{2} 2 \mathrm{H}_{2} \mathrm{O}$ in $50 \mathrm{~m}$ MTris buffer, $\mathrm{pH} 7.6$, in a $37^{\circ} \mathrm{C}$ water bath for 30 minutes (for AT1R antibody). After the endogenous peroxidase activity had been blocked, the primary and then secondary antibodies were added. Antibody binding was visualized by adding diaminobenzidine as a chromogen and hematoxylin for counterstaining. To quantify the number of inflammatory cells present, we measured AT1R-positive cells and ACE-positive cells on 20 different sections that included the wall of an arcuate artery or interlobular artery at a final magnification of 200:1 by using Image-Pro Plus Image Plus (Media Cybernetics). The average number of positive cells per section was reported for each animal.

\section{Statistical Analysis}

All data were expressed as mean value \pm standard deviation. Statistical analyses were performed with a commercially available software program (StatView 5.0; SAS Institute, Inc, Cary, NC). Differences among groups were assessed by 1-way analysis of variance followed by Bonferroni multiple comparison tests.

\section{Results}

\section{Hemodynamic Data and Renal Function}

A summary of hemodynamic characteristics obtained during the course of each experiment is given in Table 2. The pulse pressures of the LVAD group were significantly smaller than in the other groups $(28.3 \pm 8.0 \mathrm{~mm} \mathrm{Hg} \mathrm{LVAD}, 52.7 \pm 7.7$ mm Hg RVAD, $49.5 \pm 6.9$ TAH; $P<.01)$. In the LVAD group, the pulsatility index was also significantly lower than in other groups $(0.28 \pm 0.07$ LVAD, $0.56 \pm 0.08$ RVAD, $0.53 \pm 0.10$ TAH; $P<.01)$. The continuous flow RVAD pump produced reduced pulsatility in the pulmonary circulation; however, pulsatility was maintained in the systemic circulation. There was no significant difference in the mean arterial pressures. In the $\mathrm{TAH}$ group, the beat rate was significantly higher $(217.8 \pm 5.9$ beats $/ \mathrm{min} \mathrm{TAH}$, $101.3 \pm 10.0$ beats/min LVAD, $88.6 \pm 22.7$ beats $/ \mathrm{min}$ RVAD; $P<.001)$. The pump flow was $6.1 \pm 1.0 \mathrm{~L} / \mathrm{min}$ in the LVAD group, $6.1 \pm 1.4 \mathrm{~L} / \mathrm{min}$ in the RVAD group, and $10.0 \pm 0.6 \mathrm{~L} / \mathrm{min}$ in the TAH group.

\section{Pathologic Study}

All 6 calves that received a continuous flow LVAD implantation showed periarteritis in the kidneys (Figure 1, $A$ ). These results were not found in the other groups (Figure $1, B$ to $D$ ). The major pathologic findings were these: The medium-sized arteries, such as the arcuate and interlobular arteries, showed wall thickening (Figure 2, A), with abundant mononuclear cells infiltrating the periarterial areas (Figure 2, $B$ ). The arterial structure was relatively conserved and showed fewer inflammatory cells in the vascular walls. 
TABLE 2. Hemodynamics and renal function data

\begin{tabular}{lccr}
\hline Variables & LVAD & RVAD & TAH \\
\hline $\begin{array}{c}\text { Arterial pressure } \\
\text { (mm Hg) }\end{array}$ & & & \\
Systole & $116.0 \pm 9.6$ & $125.8 \pm 7.1$ & $126.4 \pm 5.7$ \\
Mean & $98.5 \pm 8.0$ & $95.1 \pm 6.3$ & $97.8 \pm 5.4$ \\
$\quad$ Diastole & $89.1 \pm 7.0$ & $73.3 \pm 4.4$ & $76.9 \pm 7.3$ \\
Heart rate & $101.3 \pm 10.0$ & $88.6 \pm 22.7$ & $217.8 \pm 5.9^{*}$ \\
$\quad$ (beats/min) & & & \\
$\begin{array}{l}\text { Pulse pressure } \\
\text { (mm Hg) }\end{array}$ & $28.3 \pm 8.0 \dagger$ & $52.7 \pm 7.7$ & $49.5 \pm 6.9$ \\
Pulsatility index & $0.28 \pm 0.07 \dagger$ & $0.56 \pm 0.08$ & $0.53 \pm 0.10$ \\
\hline
\end{tabular}

LVAD, Left ventricular assist device; RVAD, right ventricular assist device; $T A H$, total artificial heart. ${ }^{*} P<.001$ vs other groups. $\dagger P<0.01$ vs other groups.

\section{Morphometry of Renal Arteries}

Compared with the other groups, calves in the continuous flow LVAD group exhibited significantly greater wall diameter, wall thickness, and wall cross-sectional area (Table 3). There was no increase in the smooth muscle layer crosssectional area/number of smooth muscle cell count ratio in the LVAD group, suggesting that the increased wall thickness was due to hyperplasia but not hypertrophy.

\section{Immunohistochemical Findings}

AT1R was observed in the endothelial and inflammatory cells that infiltrated the periarterial and cortical interstitial areas of all animals in the LVAD group (Figure 3, $C$ and $D)$. ACE was observed in renal tubuli, endothelial cells of the renal arteries, and inflammatory cells that infiltrated the periarterial and cortical interstitial areas of all animals in the LVAD group (Figure 3,E and $F$ ). In other groups, ACE expression was seen only in the renal tubuli and in endothelial cells of renal arteries, and there were few ACEpositive reactions in inflammatory cells.

The average number of inflammatory cells in periarterial areas (pa) was significantly higher in the LVAD group $(462 \pm 190$ cells/pa LVAD, $31 \pm 21$ cells/pa RVAD, $63 \pm 36$ cells/pa TAH, $13 \pm 12$ cells/pa control; $P<.01$; Figure 4). The average number of AT1R-positive cells in periarterial areas was significantly higher in the LVAD group $(350 \pm 139$ cells/pa LVAD, $8 \pm 6$ cells/pa RVAD, $3 \pm$ 2 cells/pa TAH, $3 \pm 2$ cells/pa in control; $P<.001$; Figure 5). The average number of ACE-positive cells in periarterial areas was significantly higher in the LVAD group (325 \pm 59 cells/pa LVAD, $6 \pm 4$ cells/pa RVAD, $6 \pm 5$ cells/pa TAH, $3 \pm 1$ cells/pa control; $P<.001$; Figure 6 ). We observed a few infiltrated inflammatory cells in the TAH group; however, we did not observe visible AT1R or ACE activation in those inflammatory cells.

The immunohistochemical study showed a prominent expression of eNOS in the endothelium of renal arteries from the LVAD group (Figure 7,A) that appeared more prominent than in the other groups (Figure 7, $B$ to $D$ ).

\section{Discussion}

This study yielded two major findings: (1) Severe periarteritis in the kidney occurred only in the group implanted with a continuous flow LVAD and (2) AT1R and ACE were upregulated in mononuclear inflammatory cells in the kidneys of the continuous flow LVAD group. The significant hemodynamic differences between the LVAD group and the other groups were lower pulsatility and pulse pressure, but not mean arterial pressure.
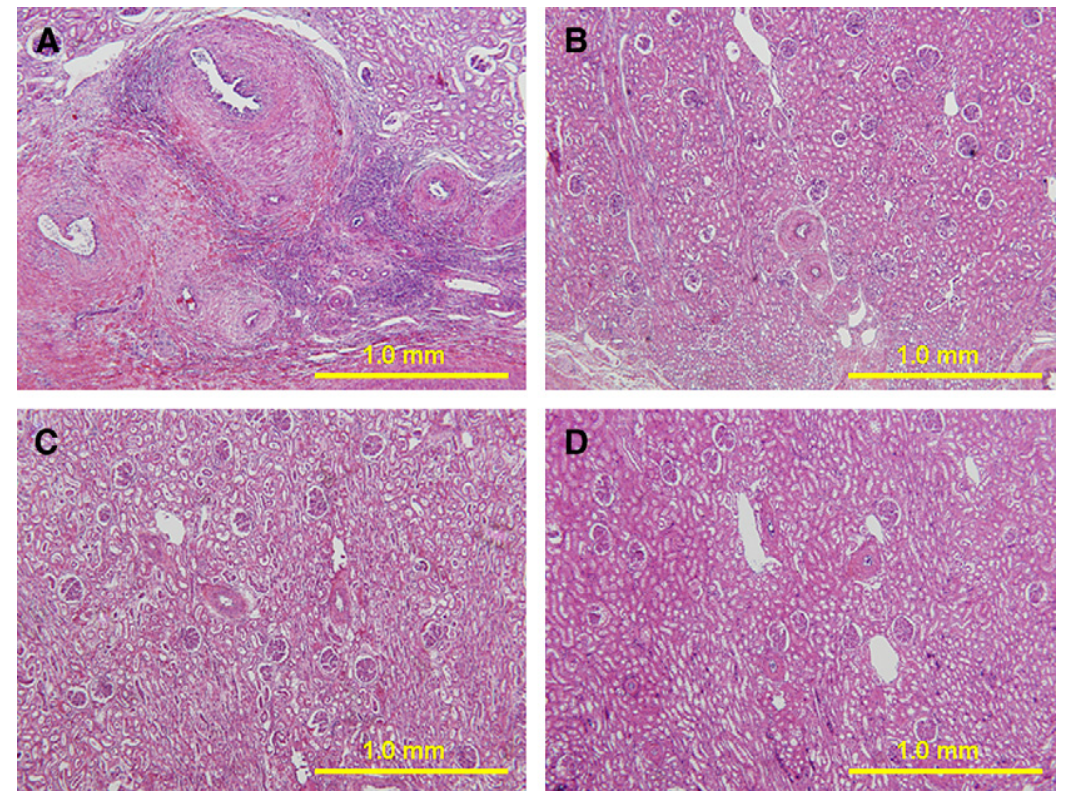

Figure 1. Hematoxylin and eosin staining of renal arteries in the corticomedullary junction area (magnification $\times 40$ ). A, Calf with continuous flow left ventricular assist device (LVAD). Extensive hyperplasia of the intima, media, and adventitia of the arteries is evident, along with mononuclear inflammatory cell infiltrates. B, Calf with continuous flow right ventricular assist device (RVAD). C, Calf with pulsatile total artificial heart (TAH). D, Control normal calf. There are no morphologic changes, suggesting that periarteritis exists in the other groups (B, C, and D). 

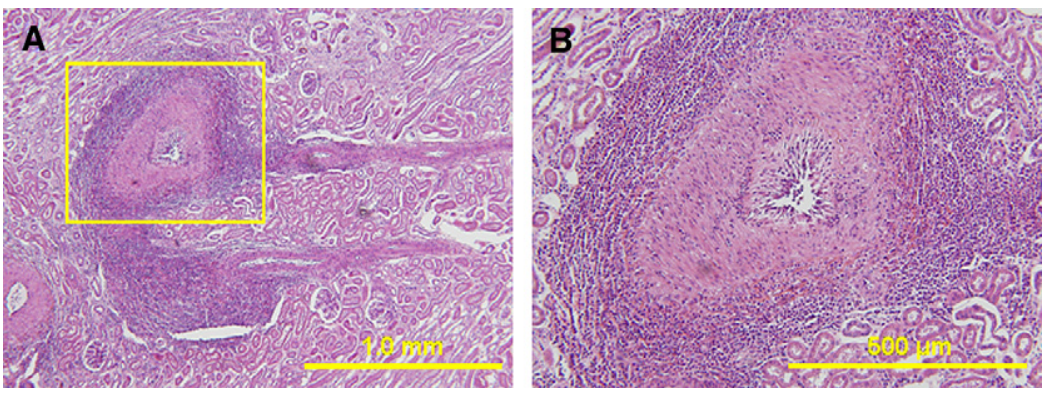

Figure 2. Hematoxylin and eosin staining of kidney in calf with continuous flow LVAD. A, The corticomedullary junction area (magnification $\times 40$ ). The medium-sized arteries, such as the arcuate artery and interlobular arteries, showed wall thickening and the presence of inflammatory cells. $B$, The arcuate artery: expanded view of area encircled with yellow line in $A$ (magnification $\times 100$ ), showing abundant mononuclear cells accumulating in the periarterial area. The artery structure is relatively conserved and has few inflammatory cells in the vascular wall. There is extensive hyperplasia of the smooth muscle layer of the media of the vessels. For abbreviations, see Figure 1.

Whether or not one needs to maintain pulsatility in the systemic circulation has been a subject of lively discussion. It is known that flow pulsatility can influence cell signaling. For example, cyclic shear stress markedly elevates eNOS activity and is associated with more sustained cytosolic calcium transients. ${ }^{14,15}$ Sustained exposure to phasic elevated hydrostatic pressure stimulates endothelial secretion of an antiproliferative factor. ${ }^{16}$ Although numerous research efforts focus on the influence of mechanical forces on gene expression and signaling through use of in vitro models of cyclic mechanical stretching on cultured vascular cells, no reliable nonpulsatile in vivo models have yet been established. Continuous flow LVAD support has been reported to cause renal cortical artery hypertrophy and inflammatory cell infiltration in the renal cortex. ${ }^{2}$ However, the mechanisms leading to this altered structure are still unclear. In this study, we investigated the effects of pulsatility in vivo on the kidney by comparing renal histologic findings for differing degrees of pulsatility produced after the implantation of different types of circulatory support devices. Our histologic analysis at multiple levels of the renal artery revealed periarteritis with smooth muscle layer hyperplasia in the animals implanted with an LVAD that produced the greatest degree of chronic reduced systemic arterial pulsatility.

We detected AT1R and ACE in mononuclear cells in the kidney after exposure to reduced pulsatile circulation. In recent years, the role of the local RAS has gained considerable attention, especially in the heart, brain, eye, testis, and kidney. ${ }^{5-9}$ Local foci of the RAS generate Ang II, which acts on resident Ang II receptors. In addition to its pressor effect, Ang II is a factor in a variety of nonhemodynamic actions, including proinflammatory, profibrogenic actions and cell growth through an AT1R, many of which are associated with cardiovascular and renal disease. ${ }^{4}$ For example, several reports have indicated the possible role of Ang II in inducing chemoattractants for monocyte/macrophage infiltration in a rabbit model of early accelerated arteriosclerosis and in a rat model of immune complex nephritis. ${ }^{17,18}$ Ang II modulates the proliferation of vascular smooth muscle cells and causes marked thickening of the vascular wall. ${ }^{19-21} \mathrm{We}$ observed many pathologic changes that can be explained by Ang II actions: (1) mononuclear cell infiltration into periarterial and interstitial areas and (2) wall thickening and vascular smooth muscle cell hyperplasia in the arcuate and interlobular arteries. One report stated that shear stress reduced ACE activity in endothelial cells. ${ }^{22}$ This result suggests that hemodynamic forces regulate the local RAS. One possible explanation for the pathologic changes in this study is that the state of reduced pulsatile circulation may activate the local RAS and elevate the Ang II level, which in turn may have induced an inflammatory reaction and vascular proliferation in the kidney.

In this study, the outflow graft of the LVAD was anastomosed to the descending thoracic aorta, whereas the majority of LVADs are likely to be anastomosed to the ascending aorta during a clinical implantation. Our healthy calf heart model

TABLE 3. Morphometric data

\begin{tabular}{lcccc}
\hline & LVAD & RVAD & TAH & Control \\
\hline Wall diameter $(\mu \mathrm{m})$ & $310.8 \pm 56.8 \dagger$ & $242.5 \pm 36.5$ & $225.7 \pm 18.1$ & $194.2 \pm 15.6$ \\
Wall thickness $(\mu \mathrm{m})$ & $121.9 \pm 27.1^{*}$ & $88.7 \pm 15.0$ & $75.1 \pm 14.0$ & $63.3 \pm 7.0$ \\
Wall thickness/diameter & $0.38 \pm 0.01$ & $0.35 \pm 0.01$ & $0.32 \pm 00.3$ & $0.34 \pm 0.03$ \\
Wall CSA $\left(\mathrm{mm}^{2}\right)$ & $13.6 \pm 5.1 \dagger$ & $9.1 \pm 3.1$ & $6.5 \pm 1.7$ & $4.8 \pm 0.5$ \\
SML CSA/nSMC $(\mu \mathrm{m} / \mathrm{cell})$ & $477 \pm 220$ & $435 \pm 107$ & $615 \pm 497$ & $330 \pm 75$
\end{tabular}

LVAD, Left ventricular assist device; RVAD, right ventricular assist device; $T A H$, total artificial heart; $C S A$, cross-sectional area; $S M L$, smooth muscle layer; $n S M C$, number of smooth muscle cells. ${ }^{*} P<.01$ vs other groups; $\dagger P<.05$ vs other groups. 

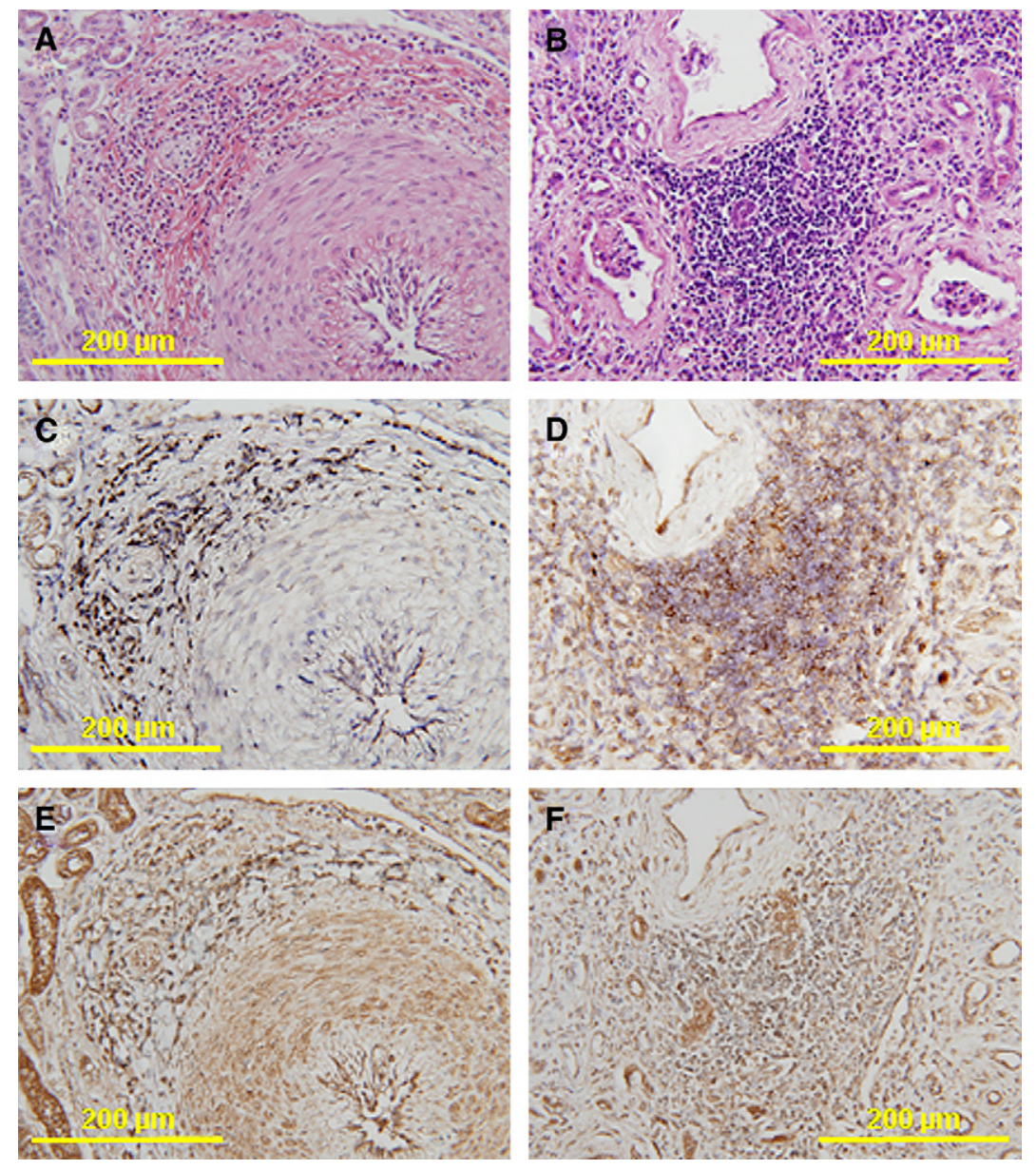

Figure 3. Histopathology and immunohistochemistry of serial sections of renal arteries from a calf with a continuous flow LVAD (magnification $\times 200$ ). Hematoxylin and eosin staining of the interlobular artery $(A)$ and cortical interstitial area (B). Immunohistochemical staining for angiotensin II type 1 receptor (AT1R) (C and D) and angiotensin-converting enzyme (ACE) (E and F). AT1R is observed in the endothelial cells and inflammatory cells that infiltrated the periarterial area (C) and cortical interstitial area (D). ACE is observed in renal tubuli, endothelial cells, the smooth muscle layer, and in inflammatory cells that had infiltrated the periarterial area (E) and cortical interstitial area (F). For abbreviations, see Figure 1. with a descending aorta anastomosis is a study limitation. One group reported that at moderate levels of continuous flow LVAD support ( $25 \%$ to $40 \%$ of cardiac output), the amount of blood flow distal to the outflow graft anastomosis decreased approximately $25 \%$ owing to increased regurgitant blood flow in the aorta. ${ }^{23}$ We considered the possibility of systemic RAS activation after LVAD implantation as a result of decreased renal perfusion and ischemic changes in the kidney. However, the pathologic diagnosis and the histologic changes in the kidney included mainly periarteritis and not ischemic changes. The systemic RAS is an endocrine system responsible for correcting acute hypotension through changes in peripheral vascular resistance and electrolyte homeostasis. $^{24,25}$ Renin release is mainly regulated by reduced renal blood pressure; renal blood flow plays only a minor role in renin release. ${ }^{26}$ We believe that our findings of AT1R and ACE up-regulation in the periarterial and cortical interstitial inflammatory cells and the fact that there was no difference in the mean arterial pressure between the groups further supports the hypothesis that the local RAS might play a major role in these histologic changes. However, more focused experiments will be needed to evaluate the relative contribu- tion of systemic and local RAS factors, including measurements of serum RAS levels and renal arterial flow and pressure after continuous flow LVAD implantations.

There are some reports on the positive effects of pulsatility on the eNOS gene expression in cultured endothelial cells and isolated blood vessels. ${ }^{14,27,28}$ Nakano and associates ${ }^{29}$ showed that increased release of nitric oxide and the activation of eNOS resulted after pulsatile pump implantation in their short-term studies. However, our immunohistochemical study showed a prominent expression of eNOS in the endothelium of renal arteries after long-term continuous flow LVAD implantation. Recent in vivo studies have shown that Ang II stimulates an increase in eNOS messenger RNA and nitric oxide production. The prominent expression of eNOS in the renal artery endothelium of this study could be explained by intervention of the local RAS. ${ }^{30}$

Implanted mechanical circulatory support systems have an inherent potential to cause systemic inflammatory responses. Ankersmit, and associate ${ }^{31}$ reported that transient immunologic activation was observed in patients receiving a continuous flow LVAD. The authors suspected that the presence of inflammatory cells may indicate immunologic 


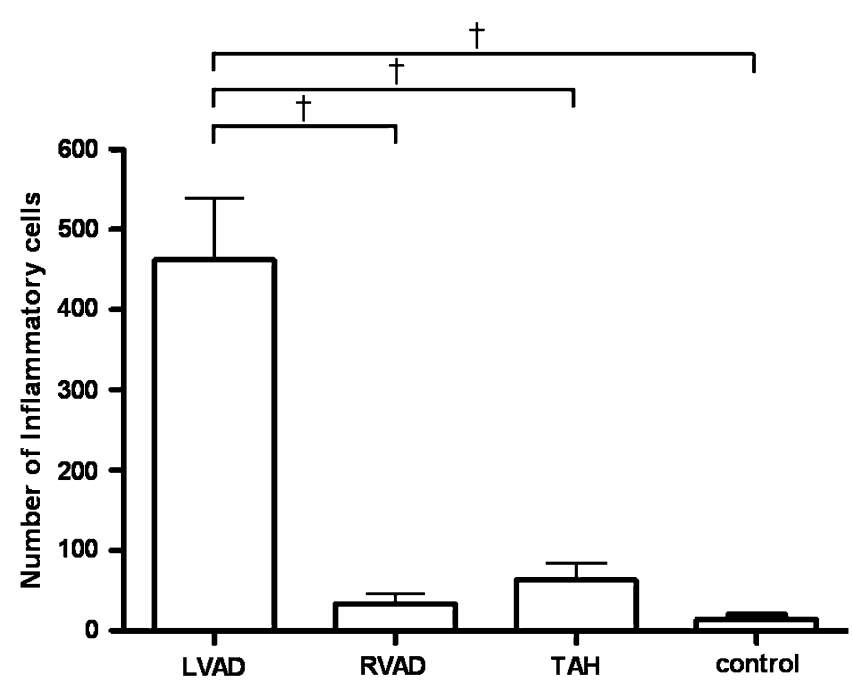

Figure 4. The number of inflammatory cells in periarterial areas from the continuous flow LVAD group was significantly higher than in the other groups. $\uparrow \boldsymbol{P}<.01$. For abbreviations, see Figure 1.

reactions. Since the LVAD and RVAD pumps used in this study were both centrifugal continuous flow pumps of the same volume and weight and were manufactured from the same material, both pumps can be regarded as the same antigen for the animals in this study. However, only those animals implanted with an LVAD showed inflammatory changes. On the basis of this result, we believe that an immunologic reaction to the LVAD blood pump was not primarily responsible for the histologic changes observed in the kidneys.

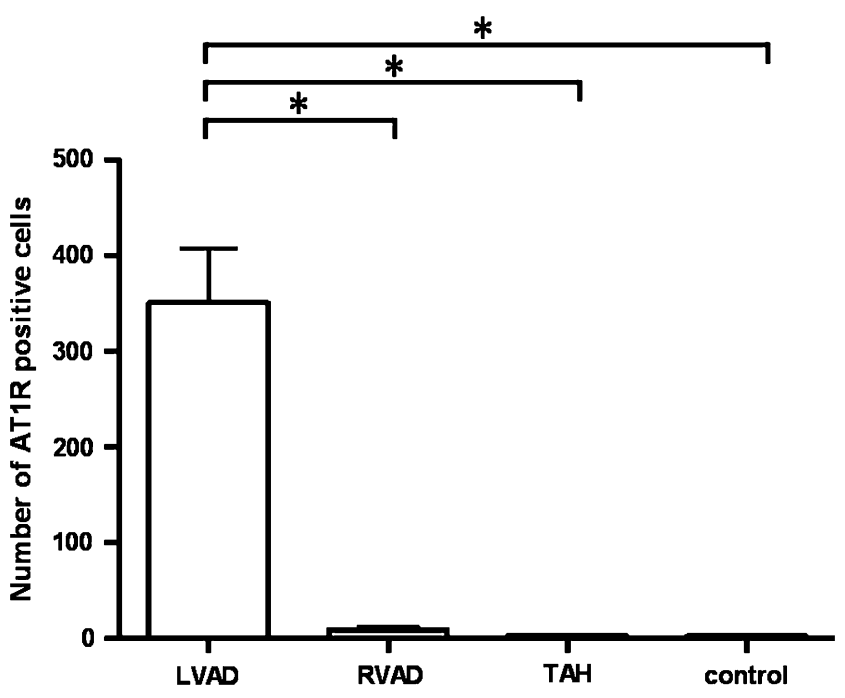

Figure 5. The number of AT1R-positive cells in periarterial areas from the continuous flow LVAD group was significantly higher than in the other groups. ${ }^{*} P<.001$. For abbreviations, see Figure 1.

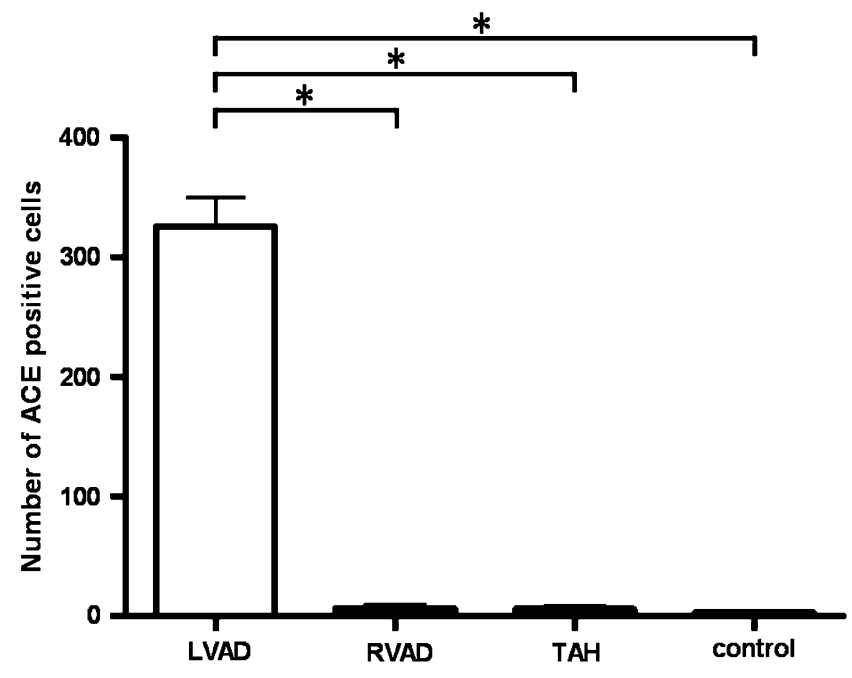

Figure 6. The number of ACE-positive cells in periarterial areas from the continuous flow LVAD group was significantly higher than in the other groups. ${ }^{*} P<.001$. For abbreviations, see Figure 1.

The positive effects of treatment with ACE inhibitors or angiotensin receptor blockers for patients with heart failure have been reported. ${ }^{32-34}$ Most patients who receive a continuous flow LVAD take these medications as part of a standard therapeutic regimen to suppress the progression of heart failure, and there is a possibility that these therapies incidentally prevent inflammatory changes such as periarteritis in the kidney. Further research will be needed to determine the effects of ACE inhibitors or angiotensin receptor blockers on the mechanisms of these pathologic changes.

As mentioned earlier, a limitation to this study is the fact that we did not measure the systemic RAS level and that the systemic arterial pressure was measured by a fluid-filled pressure-monitoring line in the carotid artery. Assessment of the histologic changes in the kidney would best be evaluated by a direct comparison of renal arterial pressure and flow measurements. Also, the immunohistochemical analyses have the possibility of nonspecific binding. A second method to confirm activation of the local RAS would strengthen this analysis. Six normal calves were used as normal histologic and immunohistochemical controls; however, we did not record hemodynamic control data from them. Incorporation of these changes into in vivo protocols is intended for further prospective studies.

In conclusion, only the continuous flow LVAD group demonstrated renal periarteritis, up-regulation of the local RAS in inflammatory cells, and reduced systemic arterial pressure pulsatility. The study design ruled out a systemic inflammatory response resulting from the blood pump biomaterials and supports the hypothesis that activity of the local RAS secondary to decreased renal arterial pressure pulsatility is the primary factor leading to these pathologic findings. 

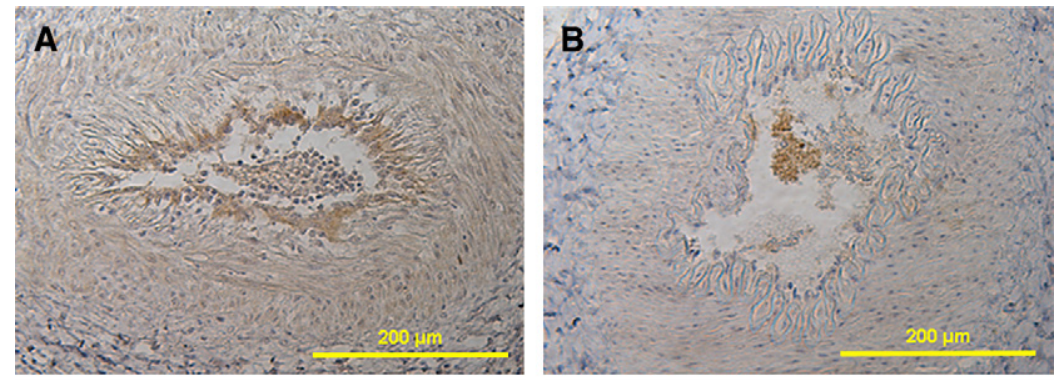

Figure 7. Immunohistochemical staining for endothelial nitric oxide synthase (eNOS) (magnification $\times 200)$. A, Calf with continuous flow LVAD. The immunohistochemical study showed a prominent expression of eNOS in the endothelium of renal arteries that appeared more prominent in LVAD group than other group. B, Calf with continuous flow RVAD. C, Calf with pulsatile-TAH. D, Control normal calf. For abbreviations, see Figure 1.
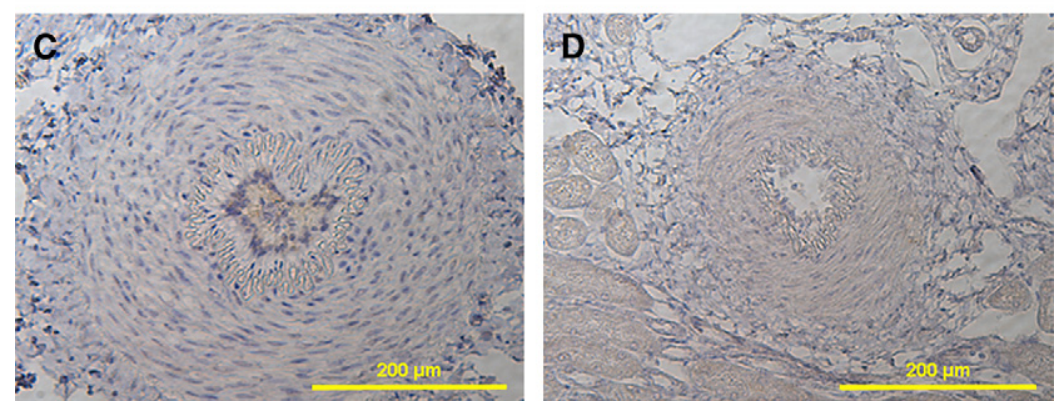

\section{References}

1. Nishimura T, Tatsumi E, Takaichi S, Taenaka Y, Wakisaka Y, Nakatani T, et al. Prolonged nonpulsatile left heart bypass with reduced systemic pulse pressure causes morphological changes in the aortic wall. Artif Organs. 1998;22:405-10.

2. Kihara S, Litwak KN, Nichols L, Litwak P, Kameneva MV, Wu Z, et al. Smooth muscle cell hypertrophy of renal cortex arteries with chronic continuous flow left ventricular assist. Ann Thorac Surg. 2003;75: 178-83.

3. Leung PS. The peptide hormone angiotensin II: its new functions in tissues and organs. Curr Protein Pept Sci. 2004;5:267-73.

4. Kim S, Iwao H. Molecular and cellular mechanisms of angiotensin II-mediated cardiovascular and renal diseases. Pharmacol Rev. 2000; 52:11-34.

5. Dostal DE, Baker KM. The cardiac renin-angiotensin system: conceptual, or a regulator of cardiac function? Circ Res. 1999;85:643-50.

6. Davisson RL, Oliverio MI, Coffman TM, Sigmund CD. Divergent functions of angiotensin II receptor isoforms in the brain. J Clin Invest. 2000; 106:103-6.

7. Wagner J, Jan Danser AH, Derkx FH, de Jong TV, Paul M, Mullins JJ, et al. Demonstration of renin mRNA, angiotensinogen mRNA, and angiotensin converting enzyme mRNA expression in the human eye: evidence for an intraocular renin-angiotensin system. Br J Ophthalmol. 1996;80:159-63.

8. Leung PS, Wong TP, Lam SY, Chan HC, Wong PY. Testicular hormonal regulation of the renin-angiotensin system in the rat epididymis. Life Sci. 2000;66:1317-24.

9. Gomez RA, Lynch KR, Chevalier RL, Wilfong N, Everett A, Carey RM, et al. Renin and angiotensinogen gene expression in the maturing rat kidney. Am J Physiol. 1988;254:582-7.

10. Ochiai Y, Golding LA, Massiello AL, Medvedev AL, Horvath DJ, Gerhart RL, et al. Cleveland Clinic CorAide blood pump circulatory support without anticoagulation. ASAIO J. 2002;48:249-52.

11. Fukamachi K, Horvath DJ, Massiello AL, Ootaki Y, Kamohara K, Akiyama M, et al. Development of a small implantable right ventricular assist device. ASAIO J. 2005;51:730-5.

12. Weber S, Kamohara K, Klatte RS, Luangphakdy V, Flick C, Chen JF, et al. MagScrew TAH: an update. ASAIO J. 2005;51: xxxvi-xlvi.

13. Amann K, Gharehbaghi H, Stephen S, Mall G. Hypertrophy and hyperplasia of smooth muscle cells of small intramyocardial arteries in spontaneously hypertensive rats. Hypertension. 1995;25:124-31.
14. Nori M, Morigi M, Donadelli R, Aiello S, Foppolo M, Todeschini M, et al. Nitric oxide synthesis by cultured endothelial cells is modulated by flow conditions. Circ Res. 1995;76:536-43.

15. Helmlinger G, Berk BC, Nerem RM. Calcium responses of endothelial cell monolayers subjected to pulsatile and steady laminar flow differ. Am J Physiol. 1995;269:367-75.

16. Vouyouka AG, Powell RJ, Ricotta J, Chen H, Dudrick DJ, Sawmiller CJ, et al. Ambient pulsatile pressure modulates endothelial cell proliferation. J Mol Cell Cardiol. 1998;30:609-15.

17. Hernandez-Presa M, Bustos C, Ortego M, Tunon J, Renedo G, RuizOrtega $\mathrm{M}$, et al. Angiotensin-converting enzyme inhibition prevents arterial nuclear factor-kappa B activation, monocyte chemoattractant protein-1 expression, and macrophage infiltration in a rabbit model of early accelerated atherosclerosis. Circulation. 1997;95:1532-41.

18. Ruiz-Ortega M, Bustos C, Hernandez-Presa MA, Lorenzo O, Plaza JJ, Egido J. Angiotensin II participates in mononuclear cell recruitment in experimental immune complex nephritis through nuclear factor-kappa $\mathrm{B}$ activation and monocyte chemoattractant protein-1 synthesis. J Immunol. 1998;161:430-9.

19. Geisterfer AAT, Peach MJ, Owens GK. Angiotensin II induces hypertrophy, not hyperplasia, of cultured rat aortic smooth muscle cells. Circ Res. 1988;62:749-56.

20. Powell JS, Clozel JP, Muller RK, Kuhn H, Hefti F, Hosang M, et al. Inhibitors of angiotensin-converting enzyme prevent myointimal proliferation after vascular injury. Science. 1989;245:186-8.

21. Campbell-Boswell M, Robertson AL Jr. Effects of angiotensin II and vasopressin on human smooth muscle cells in vitro. Exp Mol Pathol. 1981;35:265-76.

22. Rieder MJ, Carmona R, Krieger JE, Pritchard KA Jr, Greene AS. Suppression of angiotensin-converting enzyme expression and activity by shear stress. Circ Res. 1997;80:312-9.

23. Litwak KN, Kihara S, Kameneva MV, Litwak P, Uryash A, Wu Z, et al. Effects of continuous flow left ventricular assist device support on skin tissue microcirculation and aortic hemodynamics. ASAIO J. 2003;49: 103-7.

24. Peach MJ. Renin-angiotensin system: biochemistry and mechanisms of action. Physiol Rev. 1997;57:313-70.

25. Reid IA, Morris BJ, Ganong WG. The renin-angiotensin system. Annu Rev Physiol. 1978;40:377-410.

26. Nafz B, Berthold H, Ehmke H, Hackenthal E, Kirchheim HR, Persson PB. Flow versus pressure in the control of renin release in conscious dogs. Am J Physiol. 1997;273:200-5. 
27. Rubanyi GM, Romero JC, Vanhoutte PM. Flow-induced release of endothelium-derived relaxing factor. Am J Physiol. 1986;250: $1145-9$.

28. Hutcheson IR, Griffith TM. Release of endothelium-derived relaxing factor is modulated both by frequency and amplitude of pulsatile flow. Am J Physiol. 1991;261:257-62.

29. Nakano T, Tominaga R, Nagano I, Okabe H, Yasui H. Pulsatile flow enhances endothelium-derived nitric oxide release in the peripheral vasculature. Am J Physiol Heart Circ Physiol. 2000;278:1098-104.

30. Olson S, Oeckler R, Li X, Du L, Traganos F, Zhao X, et al. Angiotensin II stimulates nitric oxide production in pulmonary artery endothelium via the type 2 receptor. Am J Physiol Lung Cell Mol Physiol. 2004; 287:559-68.
31. Ankersmit HJ, Wieselthaler G, Moser B. Transitory immunologic response after implantation of the DeBakey VAD continuous-axial-flow pump. J Thorac Cardiovasc Surg. 2002;123:557-61.

32. The CONSENSUS Trial Study Group. Effects of enalapril on mortality in severe congestive heart failure. Results of the Cooperative North Scandinavian Enalapril Survival Study (CONSENSUS). $N$ Engl $J$ Med. 1987;316:1429-35.

33. The SOLVD Investigators. Effect of enalapril on survival in patients with reduced left ventricular ejection fractions and congestive heart failure. N Engl J Med. 1991;325:293-302.

34. Cohn JN, Tognoni G. Valsartan Heart Failure Trial Investigators. A randomized trial of the angiotensin-receptor blocker valsartan in chronic heart failure. N Engl J Med. 2001;345:1667-75.

Don't miss a single issue of the journal! To ensure prompt service when you change your address, please photocopy and complete the form below.

Please send your change of address notification at least six weeks before your move to ensure continued service. We regret we cannot guarantee replacement of issues missed due to late notification.

\section{JOURNAL TITLE:}

Fill in the title of the journal here.

OLD ADDRESS:

Affix the address label from a recent issue of the journal here.

\section{COPY AND MAIL THIS FORM TO:}

Elsevier Inc.

Subscription Customer Service

6277 Sea Harbor Dr

Orlando, FL 32887

\section{NEW ADDRESS:}

Clearly print your new address here.

Name

Address

City/State/ZIP
OR FAX TO:

407-363-9661

OR E-mail:

elspcs@elsevier.com
OR PHONE:

800-654-2452

Outside the U.S., call

407-345-4000 